\title{
Rehabilitation of Partial Maxillectomy Patient with a Bar and Stud Retained Hollow Bulb Obturator: A Case Report
}

\author{
Bhagyashree Kalsekar ${ }^{1}$, Paresh Gandhi ${ }^{2}$, Ajay V Sabane ${ }^{3}$, Seema S Patil ${ }^{4}$
}

\begin{abstract}
Rehabilitation of the maxillectomy defects is a challenge in terms of retention, stability, mastication, and speech. Conventional clasp designs sometimes fail to provide adequate retention, stability, and support in cases of large defects, and precision attachments are good alternatives. The use of precision attachments in partially dentate maxillectomy patients can significantly improve the functions of speech and mastication, also maintaining Esthetics. The present clinical report describes the interdisciplinary approach in rehabilitation of a partially dentate maxillectomy patient using a precision attachment retained hollow bulb definitive obturator prosthesis.

Keywords: Bar stud attachment, Maxillectomy, Obturator, Retention.

International Journal of Prosthodontics and Restorative Dentistry (2019): 10.5005/jp-journals-10019-1250
\end{abstract}

\section{BACKGROUND}

Maxillectomy is frequently an acquired defect, most commonly a result of surgical excision of carcinomas. Maxillectomy defects can be broadly categorized based on the extent of the defect, degree of hypernasal speech, nasal regurgitation, and impaired mastication. ${ }^{1}$ To overcome these problems, the obturator can be an effective treatment modality to rehabilitate the patient.

Obturator is a maxillofacial prosthesis used to close a congenital or acquired tissue opening, primarily of the hard palate and/or contiguous alveolar/soft tissue structures. ${ }^{2}$ It plays a pivotal role in separation of the oral cavity from the sinonasal cavities. ${ }^{3,4}$ Improved mastication, swallowing, articulation, speech intelligibility, etc., are additional requirements of an obturator prosthesis. $^{5-7}$

Various obturator designs have been advocated, which include open and closed hollow obturators, ${ }^{8-10}$ inflatable obturators, ${ }^{11}$ and two-piece hollow obturator prostheses. ${ }^{12}$ Hollow closed bulb obturators remain a prosthodontist's and patient's first choice. Most maxillary defects can be rehabilitated using a conventional simple obturator prosthesis. The use of multiple attachments has been described as providing increased stability and retention of the prosthesis as well as function. ${ }^{13}$

The present clinical report describes the prosthetic rehabilitation of maxillectomy defect using an attachment-retained fixedremovable hollow bulb obturator prosthesis.

\section{Case Description}

A 45-year-old patient reported to the Department of Prosthodontics and Crown and Bridge, Bharati Vidyapeeth (Deemed to be University) Dental College and Hospital, Pune, with a chief complaint of difficulty in chewing, ill fitting, and heavy prosthesis, impaired speech, and nasal regurgitation. The patient had been diagnosed with adenoid cystic carcinoma of the maxillary sinus that was treated by a unilateral maxillectomy of the right side by the maxillofacial surgeon. Extraoral examination revealed a sunken region over the right cheek and unilateral facial and lip asymmetry due to partial resection of right maxilla. Intraoral examination presented a resection of the hard palate,
${ }^{1-4}$ Department of Prosthodontics and Crown and Bridge, Bharati Vidyapeeth (Deemed to be University) Dental College and Hospital, Pune, Maharashtra, India

Corresponding Author: Bhagyashree Kalsekar, Department of Prosthodontics and Crown and Bridge, Bharati Vidyapeeth (Deemed to be University) Dental College and Hospital, Pune, Maharashtra, India, Phone: +91 9890876681, e-mail: bkalsekar26@gmail.com.

How to cite this article: Kalsekar B, Gandhi P, Sabane AV, et al. Rehabilitation of Partial Maxillectomy Patient with a Bar and Stud Retained Hollow Bulb Obturator: A Case Report. Int J Prosthodont Restor Dent 2019;9(4):134-138.

Source of support: Nil

Conflict of interest: None

alveolar bone, teeth, and soft tissue not exceeding the midline (Fig. 1). The defect was classified according to Aramany as a class I curved arch form. ${ }^{14,15}$ Remaining teeth on the contralateral posterior side were carious and fractured because of the

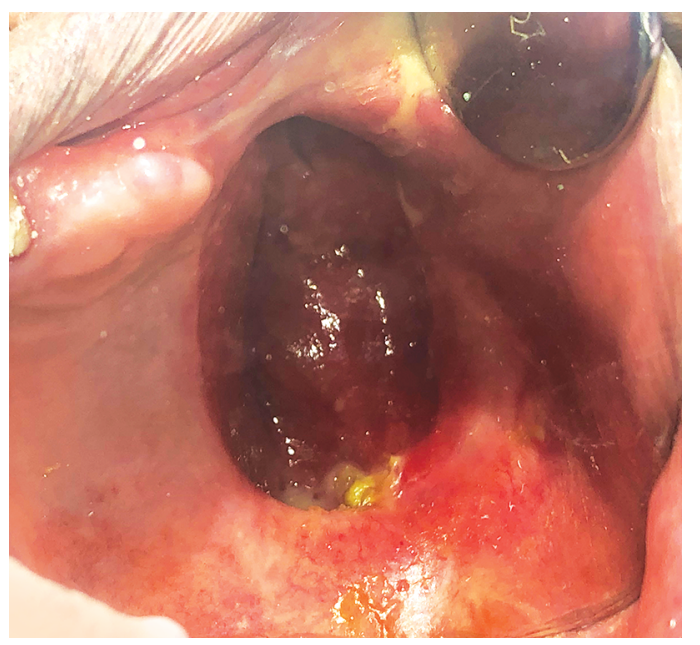

Fig. 1: Intraoral view showing the extent of the defect

(c) The Author(s). 2019 Open Access This article is distributed under the terms of the Creative Commons Attribution 4.0 International License (https://creativecommons. org/licenses/by-nc/4.0/), which permits unrestricted use, distribution, and non-commercial reproduction in any medium, provided you give appropriate credit to the original author(s) and the source, provide a link to the Creative Commons license, and indicate if changes were made. The Creative Commons Public Domain Dedication waiver (http://creativecommons.org/publicdomain/zero/1.0/) applies to the data made available in this article, unless otherwise stated. 


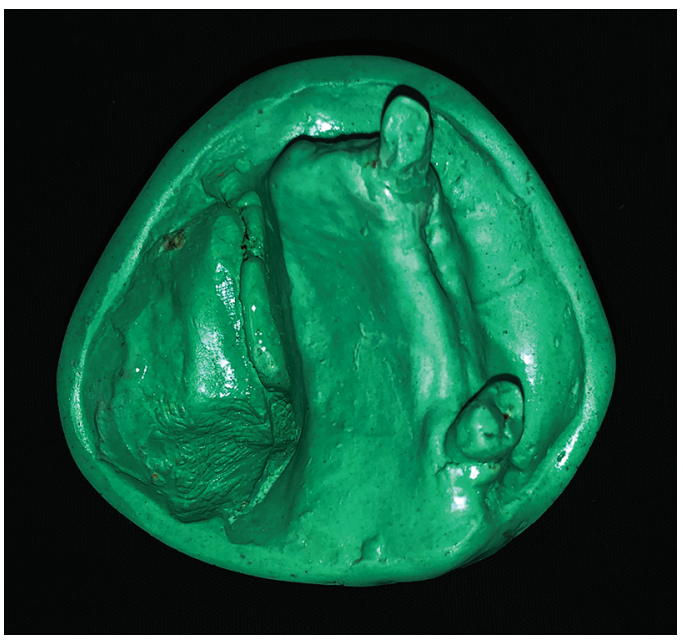

Fig. 2: Diagnostic study cast

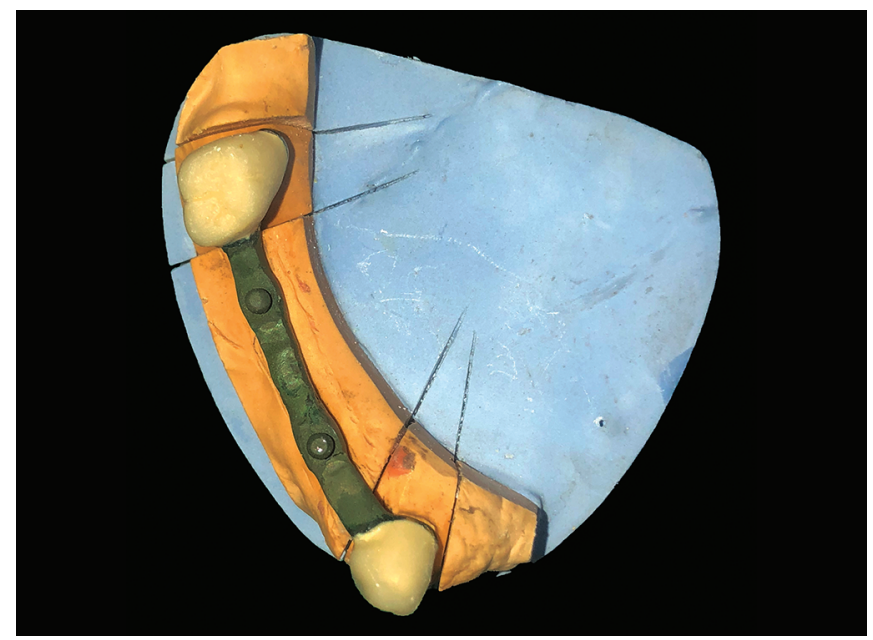

Fig. 4: Completed cast Co-Cr framework of the attachment

accumulation food and plaque at previous clasp site. Diagnostic study model was made (Fig. 2).

\section{Fabrication of the Bar Attachment to Splint the Abutment Teeth}

A fixed removable hollow bulb obturator was planned following extractions of carious and fractured teeth. The maxillary right canine and right second molar were prepared to receive porcelain fused to metal restorations. Wax patterns were fabricated for the prepared teeth and a pattern resin (GC America) custom bar running over edentulous ridge was connected to these prepared wax patterns. Ball attachment patterns (Rhein 83, USA) were attached to the custom bar in the region of second premolar and first molar (Fig. 3). The completed framework was cast made of cobalt-chromium (CoCr) alloy (dentaurum) (Fig. 4) followed by a try-in. The final pickup impression (Fig. 5) was made in a custom tray using the medium body addition silicone material (Aquasil, Dentsply, Germany) for the cast partial framework and obturator fabrication.

\section{Fabrication and Try-in of the Cast Partial Framework}

The obturator's cast partial framework was designed based on Kennedy's class II modification 1 design principles. The waxed framework was fabricated onto the duplicated model and the

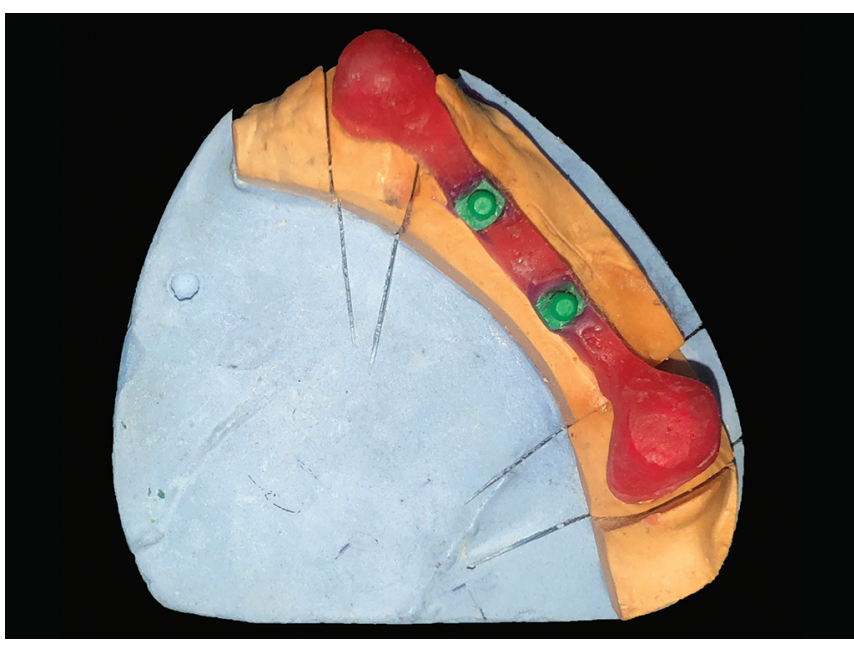

Fig. 3: Wax pattern of the custom bar and ball attachments

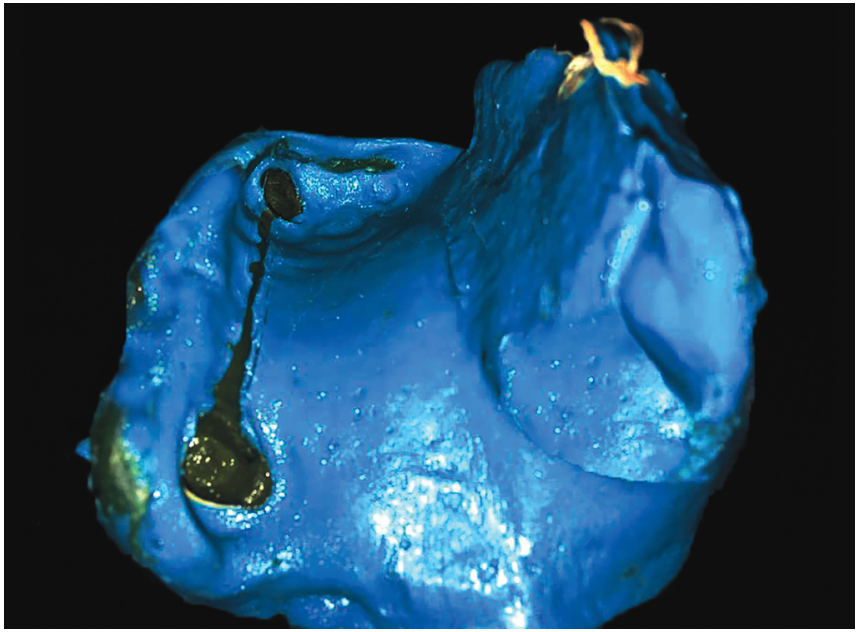

Fig. 5: Pickup impression of the attachment

processing caps were placed over the attachments and the waxed framework was cast using $\mathrm{Co}-\mathrm{Cr}$ (dentaurum) alloy (Fig. 6). The finished and polished framework was evaluated intraorally for the fit. Jaw relations were secured followed by teeth arrangement on a semiadjustable articulator (Fig. 7). The try-in of the waxed up prosthesis was performed to evaluate occlusal relationship, speech, and Esthetics.

\section{Fabrication of Hollow Bulb Obturator}

The fabrication was carried out in two parts, i.e., the base layer and the hollow obturator using Ivoclar's rapid cure material. The lost salt technique was used to make the obturator hollow from within. ${ }^{16}$ The prosthesis was then finished and polished (Fig. 8).

\section{Insertion of the Attachment Retained Hollow Bulb Obturator}

After the final cementation of the attachment, the obturator was inserted and areas of discomfort were relieved (Fig. 9). A follow-up appointment was done 24 hours after the insertion of the obturator. The patient was satisfied with the prosthesis. The patient was referred to the audiology department for speech analysis and assessment of voice nasality and the clarity of articulation. 


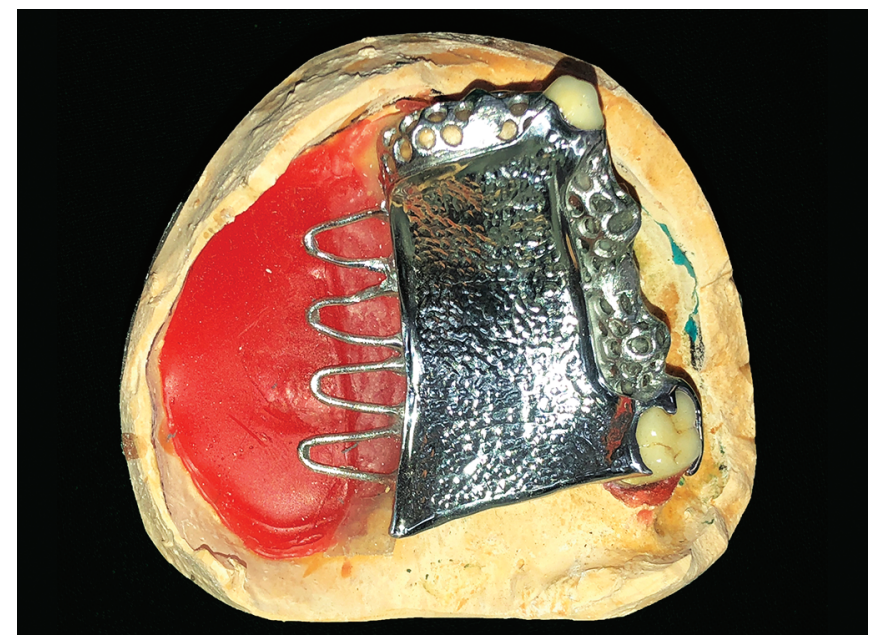

Fig. 6: Completed cast partial framework

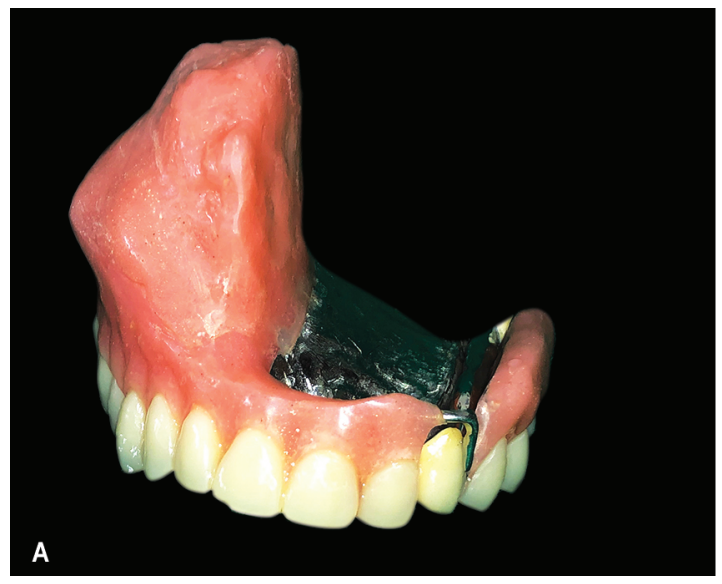

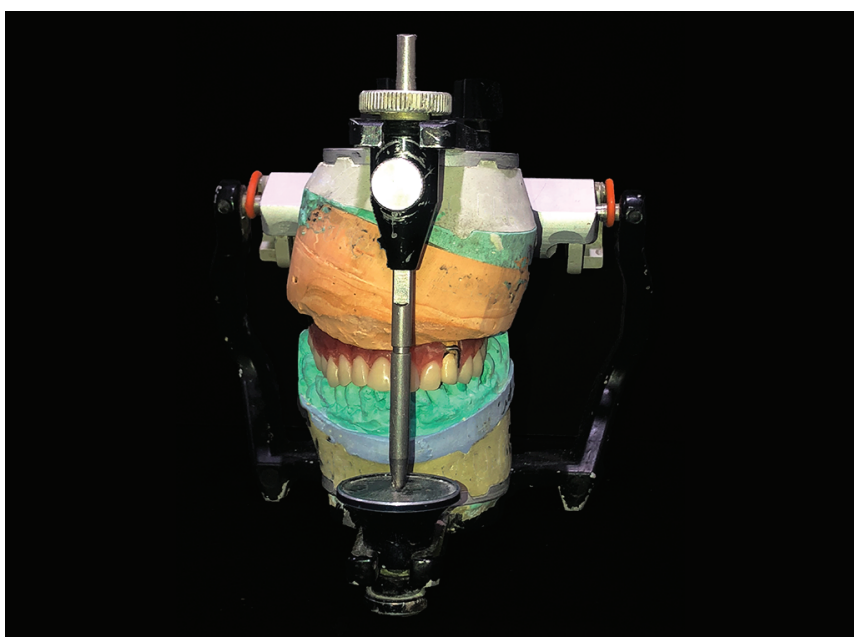

Fig. 7: Teeth arrangement on semiadjustable articulator

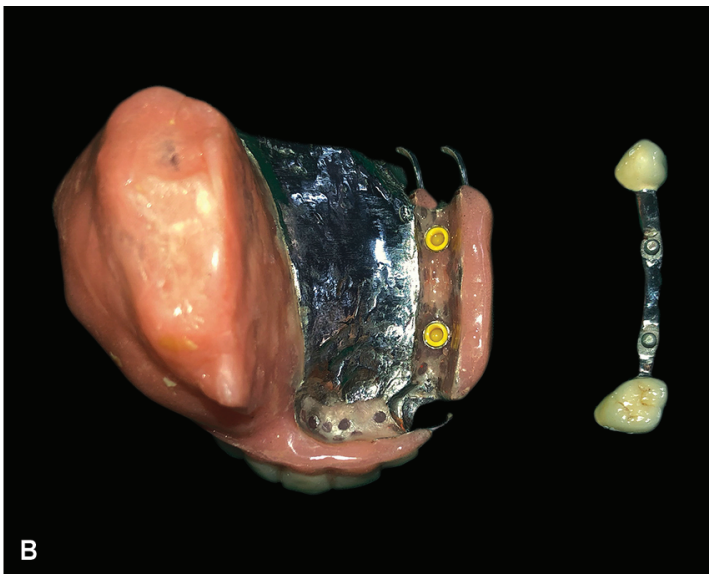

Figs 8A and B: (A) Frontal view of the finished prosthesis; (B) Intaglio surface of prosthesis showing the retention caps and attachment unit
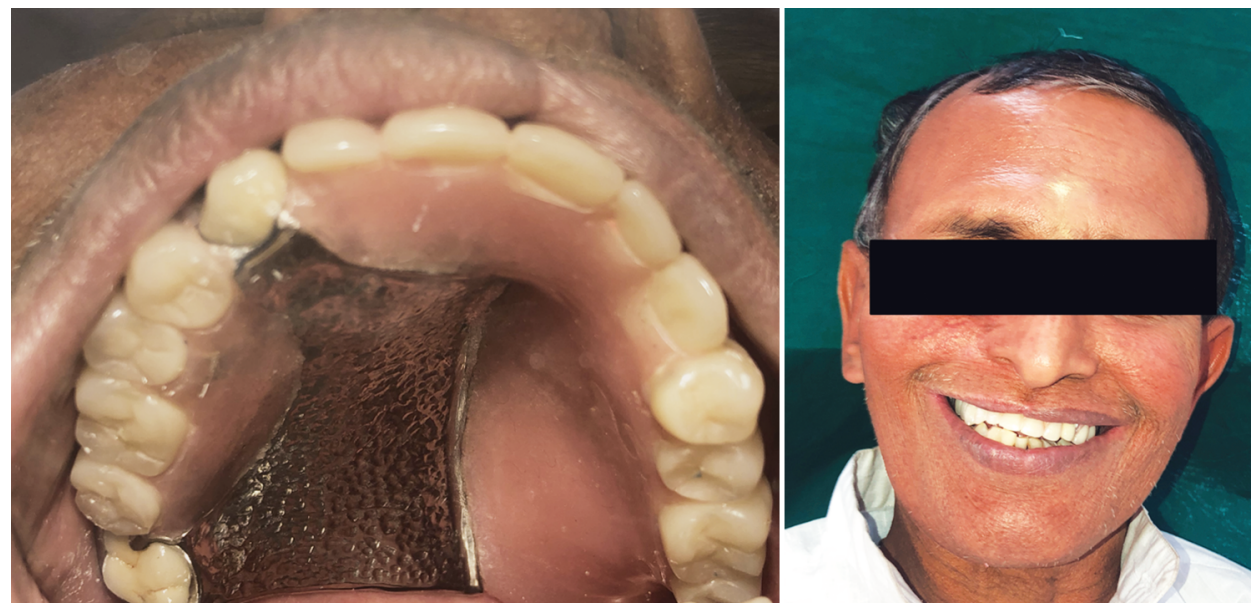

Fig. 9: Insertion of the obturator prosthesis

\section{Perceptual Analysis of Speech}

Two speech language pathologists conducted the perceptual assessment of the patient. The patient was first asked to read without the obturator in place followed by reading with the obturator in place. The speech pattern was recorded and analyzed with and without the obturator as shown in
Table 1. Following the analysis, it was noted that there was overall improvement in the clarity of speech and the patient found it easier to pronounce the $f$ and $v$ sounds after the obturator was in place. The nasalance score was assessed using the perceptual method. ${ }^{17}$ The rating scale that was used in the department for clinical purpose was as follows: 
Table 1: Perceptual analysis of speech

\begin{tabular}{lll}
\hline Parameters & Without prosthesis & With prosthesis \\
\hline a. Hypernasality & & 1 (minimal) \\
$\begin{array}{l}\text { 1. Words } \\
\text { 2. Sentences }\end{array}$ & 2 (moderate) & 1 (minimal) \\
$\begin{array}{l}\text { b. Hyponasality } \\
\text { 1. Sentences }\end{array}$ & 0 (normal) & 0 (normal) \\
$\begin{array}{l}\text { c. Voice disorder } \\
\text { d. Audible nasal air emission }\end{array}$ & 0 (normal) & 0 (normal) \\
$\begin{array}{l}\text { 1. Words } \\
\text { 2. Sentences }\end{array}$ & Present (frequent) & Present (intermittent) \\
e. Consonant production & Present (frequent) & Present (intermittent) \\
$\begin{array}{l}\text { 1. Words } \\
\text { 2. Sentences }\end{array}$ & Nasal fricative (not phoneme-specific) & Nasal fricative (not phoneme-specific) \\
$\begin{array}{l}\text { f. Nasal consonant for oral pressure consonant } \\
\text { g. Nasalized voiced pressure consonant }\end{array}$ & Nasal fricative (not phoneme-specific) & Nasal fricative (not phoneme-specific) \\
h. Speech intelligibility & Present & Present \\
$\begin{array}{l}\text { 1. Conversation } \\
\text { 2. Whole speech sample }\end{array}$ & Present & Absent \\
i. Index of intelligibility of speech (Allison et al., 1987) & 2 (difficult to understand) & 1 (mildly affected) \\
\hline
\end{tabular}

0-normal resonance, 1-mild hypernasality, 2-moderate hypernasality, 3-severe hypernasality and similar scale for speech intelligibility as mentioned in Table 1.

The nasalance score in pronunciation of words and sentences reduced from 2 to 1 following the placement of the obturator. The index of intelligibility improved from a score of 2 (difficult to understand) to a score of 5 (intelligible with occasional errors).

The patient was motivated to follow oral hygiene maintenance regularly. Regular follow-ups revealed better adaptation and improved masticatory efficiency with the prosthesis.

\section{Discussion}

Retention is a critical factor that influences the success of the prosthesis and the psychological acceptance by the patient. It is of vital importance for the patient to have satisfactory speech and masticatory efficiency. The conventional cast partial framework design for obturator prosthesis routinely employs various clasps as retentive components. ${ }^{14,15,18,20}$ The conventional cast clasps present with low capacity for retention and plastic deformation caused by repeated insertion and removal of the prosthesis. ${ }^{19,20}$ Precision attachments are considered as an excellent alternative in cases where retention is a primary concern, though they are associated with additional laboratory procedure and increased cost. The use of resilient attachment caps reduces the stress generated on the periodontally compromised abutment teeth during function. ${ }^{21}$ The fixed removable bar prosthesis design was introduced by $\mathrm{Dr}$ James Andrews. ${ }^{22}$ The advantages of such prosthesis is that it has retention and stability of a fixed prosthesis and at the same time it provides flexibility in teeth arrangement, hygiene maintenance, and Esthetics of removable prosthesis. ${ }^{22}$ The incorporation of a bar design along with ball attachments (Rhein 83) was decided for this specific case with the purpose of splinting the two widely spaced abutment teeth to equalize the force distribution and the retention was provided by the ball attachments. The nylon caps for the ball attachments are fairly economical, easily replaceable, and reduce receptacle wear. ${ }^{22,23}$ Hollow bulb obturators provide patient comfort by reducing the weight of the prosthesis. Literature describes many techniques for fabrication of closed hollow bulb using putty, cotton, salt, double flask. The technique described here does not require the double-flask method. A compendious assessment of speech intelligibility, vocal quality, nasality, and efficiency in swallowing provides important functional information for prosthetic alterations to prevent or at least reduce nasal emission while speaking and regurgitation of food while eating. The referral of these patients to the speech pathologist should be vehemently considered and put into practice by clinicians. In this case, the patient was satisfied with the outcome and his confidence reflected as he could speak with clarity and negligible nasality in voice. The retention and stability achieved through the attachments helped in enhancing patient's comfort and masticatory efficiency.

\section{Conclusion}

One of the preliminary objectives of the rehabilitation of maxillectomy patients by using the obturator is the recreation of the oronasal partition, which not only improves deglutition and mastication but also significantly enhances speech functions. We presented a case of rehabilitation of partial maxillectomy defect by using a definitive hollow bulb obturator with a bar and resilient stud attachments (Rhein 83) for achieving considerable retention and reduction in the total weight of the prosthesis. This definitive obturator served to enhance the patient's quality of the life.

\section{References}

1. Bidra AS, Jacob RF, Taylor TD. Classification of maxillectomy defects: a systematic review and criteria necessary for a universal description. J Prosthet Dent 2012;107(4):261-270. DOI: 10.1016/S00223913(12)60071-7.

2. The glossary of prosthodontic terms. J Prosthet Dent 2005;94(1):1092. DOI: 10.1016/j.prosdent.2005.03.013.

3. Okay DJ, Genden E, Buchbinder D, et al. Prosthodontic guidelines for surgical reconstruction of the maxilla: A classification system of defects. J Prosthet Dent 2001;86(4):352-363. DOI: 10.1067/ mpr.2001.119524. 
4. Etienne OM, Taddei CA. Use of bar-clip attachments to enhance the retention of a maxillofacial prosthetic obturator: a clinical report. J Oral Rehabil 2004;31(6):618-622. DOI: 10.1111/j.13652842.2004.01380.x.

5. Curtis TA, Beumer J. Restoration of acquired hard palate defects: etiology, disability, and rehabilitation. In: Beumer J, Curtis TA, Marunick MT, ed. Maxillofacial rehabilitation:prosthodontic and surgical considerations, 1st ed., St Louis: Ishiyaku Euro-America; 1996. pp. 225-284.

6. Key F. Obturator prostheses for hemimaxillectomy patients. J Oral Rehabil 2001;28(9):821-829. DOI: 10.1046/j.1365-2842.2001. 00754.x.

7. Ortegon SM, Martin JW, Lewin JS. A hollow delayed surgical obturator for a bilateral subtotal maxillectomy patient: a clinical report. J Prosthet Dent 2008;99(1):14-18. DOI: 10.1016/S0022-3913(08) 60003-7.

8. Brown KE. Fabrication of a hollow-bulb obturator. J Prosthet Dent 1969;21(1):97-103. DOI: 10.1016/0022-3913(69)90035-3.

9. Palmer B, Coffey KW. Fabrication of the hollow bulb obturator. J Prosthet Dent 1985;53:595-596. DOI: 10.1016/0022-3913(85) 90658-4.

10. Chalian VA, Barnett MO. A new technique for constructing a onepiece hollow obturator after partial maxillectomy. J Prosthet Dent 1972;28(4):448-453. DOI: 10.1016/0022-3913(72)90250-8.

11. Payne AG, Welton WG. An inflatable obturator for use following maxillectomy. J Prosthet Dent 1965;15:759-763. DOI: 10.1016/00223913(65)90049-1.

12. Cheng AC, Somerville DA, Wee AG. Altered prosthodontic treatment approach for bilateral complete maxillectomy: a clinical report. J Prosthet Dent 2004;92(2):120-124. DOI: 10.1016/ j.prosdent.2004.04.020.
13. BrudvikJS, Taylor TD. Resin bonding for maxillofacial patient. In:Taylor TD, ed. Clinical maxillofacial prosthetics. Chicago: Quintessence; 2000. pp. 53-62.

14. Aramany MA. Basic principles of obturator design for partially edentulous patients. Part I: Classification. J Prosthet Dent 1978;40(5):554-557. DOI: 10.1016/0022-3913(78)90092-6.

15. Aramany MA. Basic principles of obturator design for partially edentulous patients. Part II: design principles. J Prosthet Dent 2001;86(6):562-568. DOI: 10.1067/mpr.2001.121619.

16. Krishna C, Babu JK, Fathima T, et al. Fabrication of a hollow bulb prosthesis for the rehabilitation of an acquired total maxillectomy defect. BMJ Case Rep 2014;2014:1-4. Doi: 10.1136/bcr-2013-201400.

17. Tak HR, Waknis AP, Kulkarni SP. Perceptual and instrumental analysis of hypernasality in children with repaired cleft palate. J Cleft Lip Palate Craniofac Anomal 2016;3(2):67-72. DOI: 10.4103/2348-2125.1 87508.

18. Johnson DL. Retention for a removable partial denture. J Prosthodont. 1992;1(1):11-17. DOI: 10.1111/j.1532-849X.1992.tb00420.x.

19. Parr GR, Tharp GE, Pahn AO. Prosthetic principle of the framework design of maxillary obturator prostheses. J Prosthet Dent 1989;62(2):205-212. DOI: 10.1016/0022-3913(89)90315-6.

20. Vallittu PK, Kokkonen M. Deflection fatique of cobalt-chromium, titanium, and gold alloy cast denture clasp. J Prosthet Dent 1995;74(4):412-419. DOI: 10.1016/S0022-3913(05)80384-1.

21. Williamson RT. Removable partial denture fabrication using extracoronal resilient attachments: A clinical report. J Prosthet Dent 1993;70(4):285-287. DOI: 10.1016/0022-3913(93)90208-6.

22. Andrews JA. The Andrew's Bridge: A Clinical Guide. Covington, LA: Institute of Cosmetic Dentistry; 1976. pp. 3, 7.

23. Walid MS. Bone anchored Andrew's Bar system a prosthetic alternative. Cairo Dent J 1995;11(1):11-15. 